the rise of temperature may be connected with the rotation of the molecules in the liquid. If this hypothesis be correct, the intensity of the portion of the wing very close to the Rayleigh lines should increase and that of the other portions should diminish on dissolving a liquid in a solvent which itself gives a very feeble wing, because the quasicrystalline groups of the solute should disappear or at least their number should diminish considerably in the solution.

The wing due to cyclohexane is very feeble in comparison with that due to benzene. In order to test the above hypothesis, the distribution of intensity in the wing due to benzene on the Stokes side of the Rayleigh line $4046 \mathrm{~A}$. has been compared with that due to a 40 per cent solution of benzene in cyclohexane. The exposures in the two cases were so adjusted that the Raman line $990 \mathrm{~cm} .^{-1}$ of benzene was of the same intensity in the two spectrograms, and also the cyclohexane lines were so feeble that the wing due to cyclohexane was totally absent. A Fuess spectrograph producing absolutely no coma on the Stokes side was used. The microphotometric records of the spectrograms due to pure benzene and the mixture are reproduced as Figs. $1(a)$ and $1(b)$ respectively.

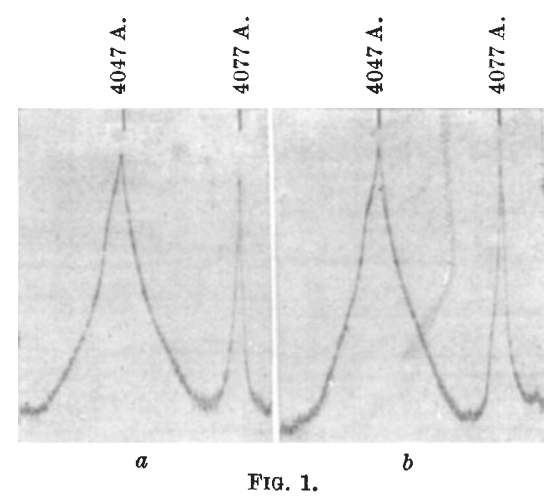

It will be seen from these figures that on dissolving benzene in cyclohexane, the intensity of the portion of the wing very close to the Rayleigh line diminishes, while that over a short region from about $50 \mathrm{~cm} .^{-1}$ from the centre of the Rayleigh line slightly increases, and also the total width of the wing remains practically unchanged. These facts are contradictory to the hypothesis of Gross and Vuks mentioned above. In fact, the intensity of the portion of the wing very close to the Rayleigh line diminishes also with the rise of temperature in the case of benzene ${ }^{2}$.

It may be briefly mentioned here that the Raman spectra of diphenyl ether and naphthalene in the solid and liquid states and also dissolved in cyclohexane have been studied by me, and it has been observed that the width of the Raman lines or bands lying very close to the Rayleigh line in the case of the solid state increases only slightly in the case of solution. The intensity of the strongest of these lines diminishes only slightly in the case of diphenyl ether and considerably in the case of naphthalene on dissolving these substances in cyclohexane. These facts suggest that these lines are not due to lattice oscillations but may be due to oscillations of very small groups of molecules which are more stable in the case of polar than in the case of non-polar mole- cules. These points will be discussed in more detail in a paper which will be published shortly in the Indian Journal of Physics.

My thanks are due to Prof. D. M. Bose for his kind interest in the work.

Palit Laboratory of Physics,

S. C. Sirkar.

92, Upper Circular Road,

Calcutta.

Sept. 20.

1 NATURE, 135, 100, $431 ; 1935$.
S. C. Sirkar and B. B.' Maiti, Ind. J. Phys., 9, 323; 1935.

\section{Back to Minkowski}

A REVIEw of my recent work on "Relativity" appeared in NATURE of October 19 under the above title. There is just one reference which might give a wrong impression, namely, where the reviewer says that the author of the work considers "that the apparent regression of the nebulæ may be interpreted as a progressive diminution in the velocity of light". This evidently refers to an article which I contributed to Engineering in 1933 and which I had reprinted as Appendix IX of the book in question.

I wish to point out that the implication of the article in question was not to suggest the explanation given but to make it clear that no experiment that could be devised would distinguish between an expansion of the universe and a progressive diminution in the velocity of light. I advanced no argument or theory in favour of one or the other. Philosophically the question is one involving the relativity of magnitude.

Dyott End,

F. W. Lanchester.

$$
\begin{gathered}
\text { Oxford Road, } \\
\text { Moseley, } \\
\text { Birmingham. } \\
\text { Oct. 25. }
\end{gathered}
$$

The reference which Dr. Lanchester thinks may give a wrong impression was founded on his Appendix IX, interpreted by the aid of $p$. $x$ of the preface -"the later discussion (Chapter xiii), in which the doctrines of general curvature and expansion are discredited"--and of pp. 13 and 124-"it is clearly without meaning to talk of the expansion of the Universe unless some part of the Universe be ex. cluded from the general expansion with which to make comparison, and then it is no longer an expansion of the Universe". If my interpretation was wrong, I must express my regrets.

H. T. H. P.

\section{South and East African Stone Age Typology}

IN my letter in NATURE of September 21, p. 475, in the fifth paragraph, I said that the oscillation which marks Bed III at Oldoway and the Intrapluvial in Pluvial II, in Uganda, "may be equated with that between the Kamasian and Gamblian" of Kenya. That was wrong, for it has recently become clear that following the Uganda Pluvial II oscillation, and separated from it by a considerable thickness of sediments, there were two less marked breaks. Study of the implements from these two non-pluvial beds reveals the fact that the last actually represents the break equivalent to that between the Kenya Kamasian and Gamblian pluvials, since in it were 